\title{
The favourable effect of catechin in electrochemotherapy in human pancreatic cancer cells
}

\author{
Olga Michel ${ }^{\circledR}$, Dawid Przystupski ${ }^{1}$, Jolanta Saczko ${ }^{1,2}$, Anna Szewczyk ${ }^{3}$, Natalia Niedzielska ${ }^{4}$, \\ Joanna Rossowska ${ }^{5}$ and Julita Kulbacka1,2
}

'Department of Medical Biochemistry, Wroclaw Medical University, Wrocław, Poland; '2Department of Molecular and Cellular Biology, Wroclaw Medical University, Wrocław, Poland; ' Department of Animal Developmental Biology, Institute of Experimental Biology, University of Wroclaw, Wrocław, Poland; ${ }^{4}$ Department of Biomedical Engineering, Wroclaw University of Technology, Wrocław, Poland; 5 Institute of Immunology and Experimental Therapy Polish Academy of Sciences, Wrocław, Poland

Until recently, green tea polyphenols were considered strong antioxidants. However, the latest reports have revealed that bioflavonoids can play a multiple role in anticancer therapy, including the inhibition of cell proliferation and generation of the oxidative stress in a dose-dependent manner. The presented research was designed to examine the potential of the green tea $( \pm)$-catechin as a reinforcement of the electrochemotherapy (ECT) with cisplatin in pancreatic cancer in vitro. The study was performed on two cell lines of the pancreatic ductal adenocarcinoma (PDA) - parental EPP85-181P and multidrug-resistant EPP85-181RNOV. Prior to the ECT protocol the cells were preincubated with high or low concentration of catechin for 2 or $\mathbf{2 4}$ hours, respectively. We assessed the influence of preincubation on the cisplatin toxicity with and without electroporation (EP), the electrosensitivity of PDA cell lines and the uptake of the daunorubicin and propidium iodide. Additionally, we evaluated the antioxidative properties of catechin by the measurement of the ROS-related fluorescence and the immunoreactivity of the oxidative stress-related enzymes superoxide dismutase (SOD2) and glutathione S-transferase (GST). We found that co-treatment with catechin can firmly enhance the efficacy of electroporation with cisplatin in vitro. More favorable effect was obtained for 2-hour incubation, which indicates the involvement of the transcriptional-independent mechanisms of catechin action. The effect may be partially explained by the increased oxidative stress level, which was higher in multidrug-resistant cells. However, further studies on cisplatin-catechin interplay and the thorough examination of the catechin-cell membrane interaction need to be performed.

Key words: electroporation, cisplatin, catechin, pancreatic cancer, in vitro

Received: 31 January, 2018; revised: 21 March, 2018; accepted: 06 April, 2018; available on-line: 22 May, 2018

e-mail: olga.michel@student.umed.wroc.pl

Abbreviations: ECT, electrochemotherapy; EP, electroporation; GST, glutathione S-transferase; PDA, pancreatic ductal adenocarcinoma; SOD2, oxidative stress-related enzymes superoxide dismutase

\section{INTRODUCTION}

\section{Epidemiology of pancreatic cancer}

Pancreatic cancer is the seventh most common cause of death due to cancer and one of the most lethal ma- lignant neoplasms across the world. The disease has a wide range of genetic alterations, including germ line and somatic mutations (Zhang et al., 2016). According to the GLOBOCAN 2012 estimates, pancreatic cancer causes more than 331000 deaths per year (Ferlay et al., 2015). The rates of incidence and mortality from pancreatic cancer were slightly higher in men than in women (Zhang et al., 2016). The main risk factors for pancreatic cancer are smoking, obesity, positive family history and genetics, diabetes mellitus, dietary factors, alcohol use and lack of physical activity (Ilic \& Ilic, 2016). The average survival time in patients with advanced pancreatic cancer is about 6 months (Long et al., 2014). At the time of diagnosis as many as $80-85 \%$ of patients are not amenable to surgery due to local vascular invasion and/ or distant metastases (Kommalapati et al., 2018). Systemic palliative treatment slightly extends the survival time and does not increase the percentage of long-term experiences. Radical surgical treatment is the only method to obtain recovery due to the high resistance of pancreatic cancer to treatment with chemotherapeutics (Wong et al., 2017). Severe complications and lack of effects after the use of cytostatics put modern medicine in front of the search for more effective and less severe side effectsabundant therapies. One approach is to include the substances of natural origin, such as green tea polyphenols, into the pancreatic cancer therapy.

\section{Cellular effect of catechin}

The green tea catechins constitute almost a three fourths of extracts derived from green tea leaves (Sang et al., 2011). Each catechin consist of polyphenolic backbone with the dihydroxyl or trihydroxyl substitutions on the $\mathrm{B}$ ring and the m-5,7-dihydroxyl substitutions on the A ring (Balentine et al., 1997a). The catechin backbone may be enlarged by the trihydroxyl structure in the $\mathrm{D}$ ring (gallate) forming (-)-epigallocatechin-3-gallate (EGCG) and (-)-epicatechin-3-gallate (ECG). Tea extracts have been shown to react with reactive oxygen species (ROS), such as superoxide radical, singlet oxygen, hydroxyl radical, peroxyl radical, nitric oxide, nitrogen dioxide, and peroxynitrite (Hussain et al., 2005; Tao et al., 2015; Chen et al., 2016). It is known that EGCG and other catechins can directly scavenge ROS and chelate free transition metals, thereby reducing oxidative stress (Forester \& Lambert, 2011). However, recent studies have demonstrated that the tea polyphenols could also generate ROS that stimulate upregulation of the endogenous antioxidant systems through activation of the Nrf2 signaling pathway (Shen et al., 2005). High concentrations 
of generated ROS could in turn lead to toxicity. Some of the related studies will be discussed subsequently.

Tea polyphenols have significant potential as cancer chemopreventive agents against chemical carcinogen- or UV radiation-induced carcinogenesis in internal body organs, such as stomach, lung, liver, pancreas, esophagus, duodenum, breast, and colon, when assessed in specific tumor bioassay models. Several theories have been put forward, including inhibition of UV- and tumor promoter-induced ornithine decarboxylase, cyclo-oxygenase, and lipoxygenase activities, antioxidant and free radical scavenging activity; enhancement of antioxidant (glutathione peroxidase, catalase, and quinone reductase) and phase II (glutathione-S-transferase) enzyme activities; inhibition of lipid peroxidation, and anti-inflammatory activity (Schuijer \& Berns, 2003; Zhang et al., 2009; Hagen et al., 2013; Hosseinimehr et al., 2013; Song et al., 2014; Chen et al., 2016). These properties of tea polyphenols make them effective chemopreventive agents against the initiation, promotion, and progression stages of multistage carcinogenesis (Katiyar \& Mukhtar, 1997). Polyphenols from green tea extract can exert a growth-suppressive effect on human pancreatic cancer cells in vitro. Qanungo et al. (2005) observed that the antiproliferative action of epigallocatechin gallate on pancreatic carcinoma is mediated through programmed cell death or apoptosis as evident from nuclear condensation, caspase-3 activation and poly-ADP ribose polymerase (PARP) cleavage (Qanungo et al., 2005). EGCG induced apoptosis of pancreatic cancer cells is accompanied by growth arrest at an earlier phase of the cell cycle (Basu \& Haldar, 2009). Catechins also invoke Bax oligomerization and depolarization of mitochondrial membranes to facilitate cytochrome $c$ release into cytosol (Roy et al., 2010). EGCG-induced downregulation of IAP family member X chromosome linked inhibitor of apoptosis protein (XIAP) might be helpful to facilitate cytochrome c mediated downstream caspase activation (Qanungo et al., 2005). Furthermore, green tea polyphenols elicited the production of intracellular reactive oxygen species (ROS), as well as the c-Jun Nterminal kinase (JNK) activation in pancreatic carcinoma cells. Interestingly, the inhibitor of JNK signaling pathway as well as the antioxidant $\mathrm{N}$-acetyl-L-cysteine (NAC) blocked polyphenols-induced apoptosis (Qanungo et al., 2005). Appari and coworkers (2014) examined the efficacy of various catechins and the combination of these bioactive agents in the primary PDA cell line and nonmalignant pancreatic ductal cells. Whereas each agent strongly inhibited colony formation, epicatechin gallate and catechin gallate were more effective than EGCG. A mixture of green tea catechins significantly induced apoptosis and inhibited viability, migration, expression of MMP-2 and -9, ALDH1 activity, colony and spheroid formation (Appari et al., 2014).

\section{Electroporation in pancreatic cancer}

Over the past 20 years, survival of patients grappling with pancreatic cancer has increased only by $3 \%$ (from 5 to $8 \%$ ), therefore greatest hopes are connected to experimental regimens (Goess \& Friess, 2018). Electroporation $(\mathrm{EP})$ is a phenomenon occurring in cells after subjection to the action of external electric field. Currently, irreversible electroporation (IRE) is gaining importance in the treatment of the locally advanced pancreatic cancer either as a margin accentuation or as primary tumor treatment (Ruarus et al., 2018). IRE is directed to a destruction of cellular membranes, whilst preserving the extracellular matrix, blood vessels and bile ducts (Vroomen et al., 2017). This was reflected by increased overall survival (20 vs 13 months) in comparison to standard treatment (Martin et al., 2013). However, several confounders connected to IRE remain, such as the inconsistency of protocols or relatively high complication rate (Ruarus et al., 2018). Promising approach in the PDA treatment is the electrochemotherapy (ECT) in which electric field is applied in order to temporarily increase the permeabilization (hence, it is often called "electropermeabilization"), allowing the membrane penetration by the hydrophilic therapeutic agents. Although the data on ECT application in pancreatic cancer are limited, preliminary results indicate the feasibility and safety of this method for the locally advanced disease (Granata et al., 2015). According to recent reports, following ECT application in $19 \mathrm{pa}-$ tients with locally advanced pancreatic cancer, depending on the criteria, 60 to $100 \%$ patients showed a partial response to treatment (Granata et al., 2017). However, the mechanisms of ECT application in pancreatic cancer remain poorly understood. Here, we propose a method for the enhancement of EP efficacy by means of catechin natural compound found in green tea. Our study aims to demonstrate the effect of catechin on the efficacy of electroporation in pancreatic cancer cells with different levels of drug resistance.

\section{MATERIAL AND METHODS}

Cell cultures. The study was carried out on two cell lines of pancreatic ductal adenocarcinoma: the parental human cell line, sensitive to daunorubicin (EPP85-181P) and the MDR1/P-gp-independent atypical MDR cell line, selected against mitoxantrone (EPP85-181RNOV). The cultures were maintained in $37^{\circ} \mathrm{C}$ under high humidity in the Steri-Cult $\mathrm{R}$ Automated $\mathrm{CO}_{2}$ Incubator (Thermo Fisher Scientific). As a culture medium we used modified Leibovitz (L-15) medium (Gibco, Life Technologies, Carlsbad, CA) supplemented with $10 \%$ fetal bovine serum, 1\% antibiotics solution (10000 units penicillin and $10 \mathrm{mg}$ streptomycin/mL, Sigma, Saint Louis, MO), $1.5 \%$ sodium bicarbonate $(7.5 \%$, Gibco), 1\% MEM vitamin solution (Sigma), 0.5\% ultraglutamine (Lonza, Basel, Switzerland), $0.1 \%$ glucose (45\%, Sigma), $1 \%$ insulin (Sigma) and $0.7 \%$ aprotinin (5 TIU in $1 \mathrm{~mL}$ PBS buffer; BioShop, Canada).

Drugs. Both drugs were freshly prepared each time prior experiments. ( \pm )-Catechin hydrate (Sigma, cat no. C1788) was firstly dissolved in $99 \%$ ethanol to the $10 \mathrm{mM}$ concentration and subsequently diluted to 5-100 $\mu \mathrm{M}$ concentration with culture medium for cytotoxicity tests or preincubation. The final concentrations of ethanol in samples was up to $\sim 1 \%$, which was proven to be non-toxic for cells prior to the study. For EP experiments catechin was diluted to $10 \mu \mathrm{M}$ with EP buffer of a composition described previously (Kulbacka et al., 2014). Cis-Diamineplatinum(II) dichloride (Sigma, cat. no. 479306) was dissolved in the PBS buffer to the concentration of $5 \mathrm{mM}$ and then diluted with culture medium $(5-100 \mu \mathrm{M})$ for cytotoxicity test or with EP buffer $(5$ and $10 \mu \mathrm{M})$ for the electroporation protocol.

Electroporation protocol. Prior to the electroporation (preceded or not by the catechin preincubation) cells were collected with trypsin and placed in dedicated cuvettes containing EP buffer of low conductivity (Kulbacka et al., 2014). Then, for some cells drugs (cisplatin or mix of catechin/cisplatin) were added and part of the samples were electroporated. The parameters for the EP were as follows: 8 pulses of $100 \mu$ s duration with 


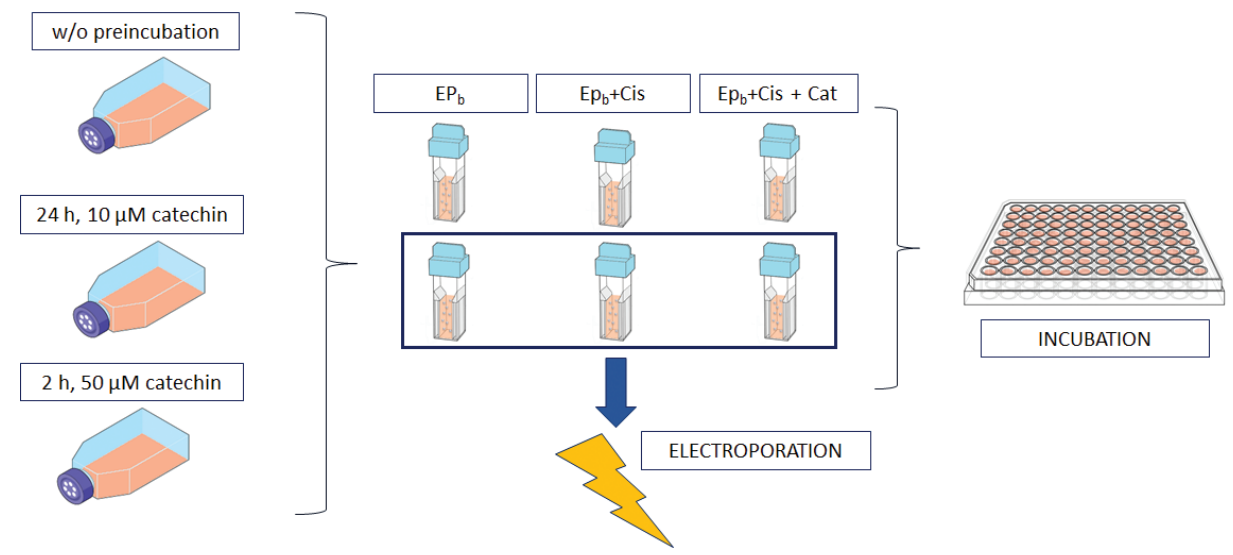

Figure 1. The procedure of the electroporation preceded by catechin preincubation versus the procedure of electroporation not preceded by catechin preincubation ( $\mathrm{EP}_{\mathrm{b}}$ - electroporation buffer, $\mathrm{Cis}-10 \mu \mathrm{M}$ cisplatin, Cat - $10 \mu \mathrm{M}$ catechin). Electroporation was performed with the electric field intensity of $1000 \mathrm{~V} / \mathrm{cm}$.

$0-1600 \mathrm{~V} / \mathrm{cm}$ range of electric field intensity and $5 \mathrm{kHz}$ frequency with the BTX 830 square wave electroporator (BTX Harvard Apparatus, Syngen Biotech, Wroclaw, Poland). After electroporation, the cells were incubated for 10 minutes in $37^{\circ} \mathrm{C}$, centrifuged $(5 \mathrm{~min}, 1400 \times \mathrm{g})$ and then seeded on multiwell plates. The scheme of the applied electroporation protocol is shown above (Fig. 1).

MTT assay. Following the experiments of chemosensitivity testing and electrochemotherapy in vitro, we determined the cells' viability via MTT assay (3-(4,5-dimethylthiazol-2-yl)-2,5-diphenyltetrazolium bromide, Sigma) as a function of redox potential. After 24, 48- or 72 -hour incubation, the medium was removed from the wells and replaced with MTT $^{\top}$ solution $(0.5 \mathrm{mg} / \mathrm{ml}$ PBS buffer), then incubated in $37^{\circ} \mathrm{C}$ for 2 hours. The resulting formazan crystals were dissolved with the mixture of isopropanol (Archem, Poland) and $0.4 \%$ of hydrochloric acid ( $\mathrm{HCl}$, Archem, Poland). The absorbance was measured with a multiwell scanning spectrophotometer at $570 \mathrm{~nm}$ (EnSpire Multimode Plate Reader, Perkin Elmer, Waltham, Massachusetts/USA). The viability was expressed as a percentage of treated cells compared to the non-treated control.

Immunocytochemical staining ABC. For the examination of the immunoreactivity of superoxide dismutase (SOD2) and glutathione S-transferase (GST) cells were seeded on 12-well diagnostic slides (Thermo Fisher Scientific). After 24 hours in $\mathrm{CO}_{2}$ incubator, the medium above cells was replaced with a culture medium containing catechin. The cells were subsequently incubated in $37^{\circ} \mathrm{C}$ for 24 hours with $10 \mu \mathrm{M}$ catechin or for 2 hours with $50 \mu \mathrm{M}$ catechin. After this time, the cells were fixed in 4\% paraformaldehyde (Roth, Germany) and stained with the EXPOSE Mouse and Rabbit Specific HRP/ DAB Detection IHC kit (Abcam, United States; cat. no ab80a36). For the overnight incubation we used following antibodies: mouse monoclonal anti-SOD2 (Thermo Fisher Scientific; cat. no. LF-MA0030) and rabbit polyclonal anti-GST (Z-5) (Santa Cruz, cat no. sc-459), both diluted 1:200 with the PBS buffer. After the two-day procedure samples were analyzed in a double-blinded manner with the upright microscope (Olympus BX51, Japan). The immunoreactivity was determined semiquantitatively as a percentage of positive cells stained (from a total of 150 cells per sample). The intensity of immunocytochemical staining was evaluated from five different fields of view per sample and marked as: $(-)$ negative, $(+)$ weak, $(++)$ moderate and $(+++)$ strong, according to scale developed in the laboratory.
DCF assay. The level of the reactive oxygen species (ROS) in cells was determined with the DCF (2,7-dichlorofluorescein) assay (Life Technologies, Poland). The DCF assay is conducted with 6-carboxy-2,7-dichlorodihydrofluorescein diacetate 2,7-dichlorofluorescein (carboxy- $\mathrm{H}_{2} \mathrm{DCFDA}$ ) which is a chemically reduced form of fluorescein used as an indicator for the quantitative measurement of ROS in cells. After cleavage of the acetate groups by intracellular esterase and oxidation, non-fluorescent $\mathrm{H}_{2} \mathrm{DCFDA}$ transforms into highly fluorescent 2',7'-dichlorofluorescein (DCF). The intensity of DCF fluorescence in cells determines the level of the intracellular ROS synthesis, proportionally to the intensity of DCF fluorescence in cells. The cells were trypsynized and seeded on black 96-well plates (Perkin Elmer) for 24 hours. Then, the medium was replaced with the medium-catechin solutions and cells were preincubated for $24 \mathrm{~h}$ with $10 \mu \mathrm{M}$ catechin or $2 \mathrm{~h}$ with $50 \mu \mathrm{M}$ catechin. After that time medium was removed afresh and the cells were incubated for $4 \mathrm{~h}$ with $5 \mu \mathrm{M}$ cisplatin, $10 \mu \mathrm{M}$ cisplatin, or mixture of $10 \mu \mathrm{M}$ cisplatin with $10 \mu \mathrm{M}$ catechin. Then, the DCF assay was performed. For experiments, the stock solution of carboxy- $\mathrm{H}_{2}$ DCFDA $(50 \mu \mathrm{g}$ / $\mathrm{mL}$ in sterile DMSO; Sigma, Poland) was established at the RT in the dark and then diluted in a cell culture medium without FBS. After washing out with PBS the reagent was added to cell culture to a final concentration 1 $\mu \mathrm{M}$ and was incubated at $37^{\circ} \mathrm{C}$ in darkness for $30 \mathrm{~min}$. After the incubation, the fluorescence of DCF in wells (five replicated per sample) was detected every 15 minutes for 90 minutes total (with excitation wavelength of $495 \mathrm{~nm}$ and the emission wavelength of $530 \mathrm{~nm}$ ).

FACS analysis. Flow cytometry analysis was performed for the assessment of the cell ability to internalize propidium iodide (PI) and daunorubicin (DB) into the pancreatic cancer cells. The cells were collected with Trypsin-EDTA and subjected to EP protocol described in the previous subsection. Immediately before EP, propidium iodide (Sigma; cat. no. P4170) or daunorubicin at a $10 \mu \mathrm{M}$ concentration was applied to the cell suspension. After electroporation and 10-minute incubation in $37^{\circ} \mathrm{C}$ in $\mathrm{CO}_{2}$ incubator, the cells were washed in PBS and resuspended in $0.5 \mathrm{ml}$ of PBS. Flow cytometric analysis was performed on a FACS Calibur flow cytometer (Becton Dickinson). The fluorescence of PI was measured with FL-3 detector with 670LP emission filter. At least 10000 viable cells were measured from each sample at a rate of up to 1000 cells/s. 
Statistical analysis. Each experiment was performed three times, in triplicate for each parameter (for a total of 9 replicates per parameter), unless pointed differently. The data was presented as the mean \pm S.D. The experiment on catechin cytotoxicity was analyzed via Student's $t$-test where following samples were compared to non-treated control. For the experiments with catechin preincubation multiple comparisons were performed where each parameter was compared to the same parameter of non-treated control. Statistically significant differences between treated samples and non-treated controls were placed on graphs with $P$-value of $p \leq 0.05$ considered significant. All statistical calculations were performed with Microsoft Excel, GraphPad Prism 7 and Statistica 13.1 software.

\section{RESULTS}

The study on the catechin influence on PDA cell lines

The cytotoxicity of catechin towards sensitive and resistant cell lines

The parental cell line sensitive to daunorubicin EPP85-181P and the multidrug-resistant cell line EPP85181 RNOV showed similar response to the low concentrations of catechin (Fig. 2). The viability of sensitive cells was slightly more disturbed, in particular after 72 hours of incubation, when the mitochondrial activity was decreased by approximately $37 \%$ in comparison to the non-treated control. Two concentrations were selected for the subsequent experiments: $10 \mu \mathrm{M}$ for the electroporation protocol and 24-hour preincubation and $50 \mu \mathrm{M}$ for 2-hour preincubation.
The influence of catechin preincubation on the cytotoxicity of cisplatin.

The effect of preincubation on the cisplatin cytotoxicity was unequal for the tested cell lines (Fig. 3). Whilst for the parental cell line EPP85-181P the long-term incubation had no impact on the viability and the shortterm incubation reduced the toxicity of cisplatin, for the drug-resistant cell line EPP85-181RNOV the cisplatin's concentrations at a range of 15 to 50 were more toxic when the cells were preincubated prior to the cytotoxicity assay. However, for the highest cisplatin concentration the protective role of $10 \mu \mathrm{M}$ catechin preincubation was evident in both cell lines.

\section{The involvement of the catechin preincubation in the oxidation and detoxication}

The production of the reactive oxygen species (ROS)

To examine the effect of catechin preincubation on the cells' ability to neutralize ROS we performed the DCF assay. For both cell lines of pancreatic cancer preincubation with $50 \mu \mathrm{M}$ catechin was supporting the process more efficiently, which was especially visible in cells not subjected to the subsequent incubation with cisplatin (Fig. 4, cis 0 $\mu \mathrm{M})$. However, when cisplatin was combined with catechin (cis $10 \mu \mathrm{M}+$ cat $10 \mu \mathrm{M}$ ), the level of ROS increased, which indicates an additive effect of catechin and cisplatin resulting in the oxidative stress occurrence (Fig. 4B, D).

The immunoreactivity of the mitochondrial superoxide dismutase (SOD2) and glutathione S-transferase (GST)

The immunoreactivity of the superoxide dismutase increased in daunorubicin-sensitive cell line EPP85-
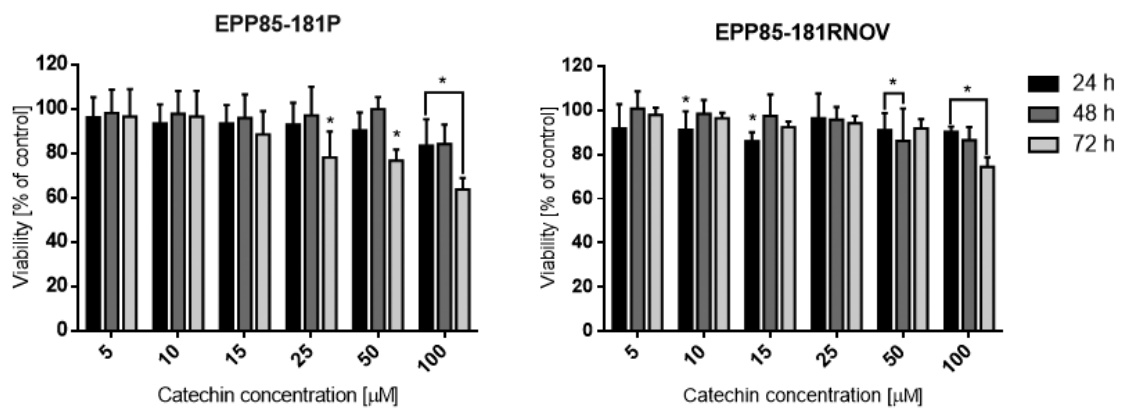

Figure 2. The viability of PDA cell lines EPP85-181P (parental) and EPP85-181RNOV (multidrug-resistant) measured with MTT assay following the 24, 48 and 72-hour incubation with different concentrations of catechin.

*statistically significant differences between catechin-treated groups and the non-treated control $(p \leq 0.05)$.
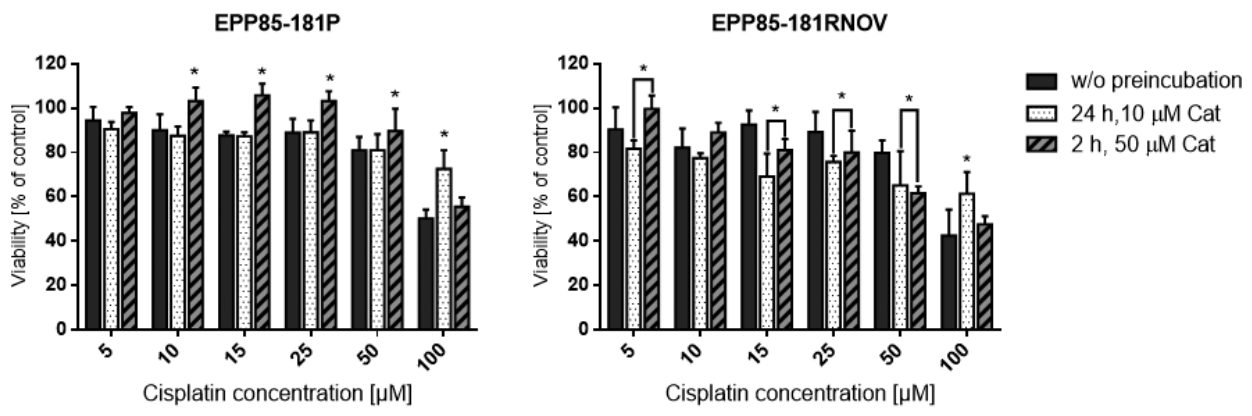

Figure 3. The viability of PDA cell lines EPP85-181P (sensitive to daunorubicin) and EPP85-181RNOV (multidrug-resistant) measured with MTT assay, following 48-hour incubation with cisplatin not preceded by catechin preincubation versus preceded by preincubation with $10 \mu \mathrm{M}$ catechin for 24 hours or with $50 \mu \mathrm{M}$ catechin for 2 hours.

*statistically significant differences between groups treated with catechin and non-treated control $(p \leq 0.05)$. 
A EPP85-181P; $10 \mu \mathrm{M}$ catechin preincubation

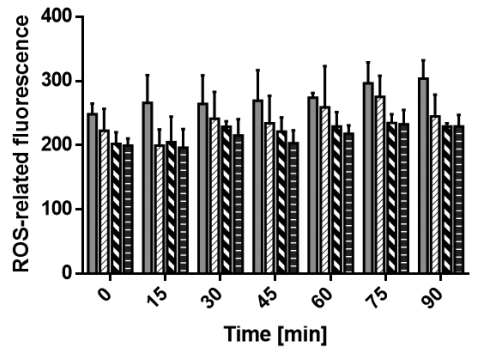

C EPP85-181RNOV; $10 \mu \mathrm{M}$ catechin preincubation

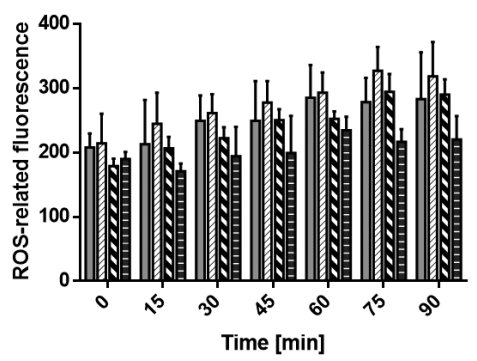

B EPP85-181P; $50 \mu \mathrm{M}$ catechin preincubation

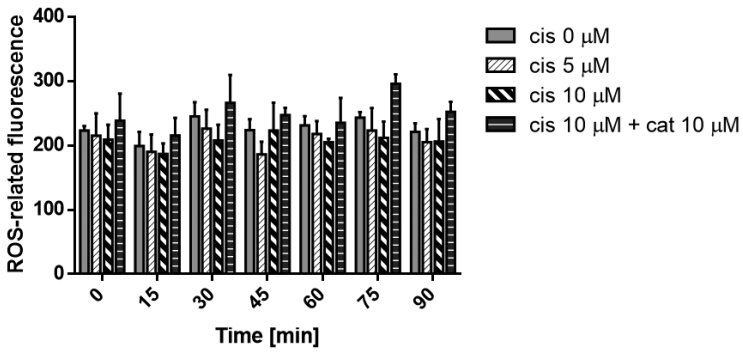

D EPP85-181RNOV; $50 \mu M$ catechin preincubation

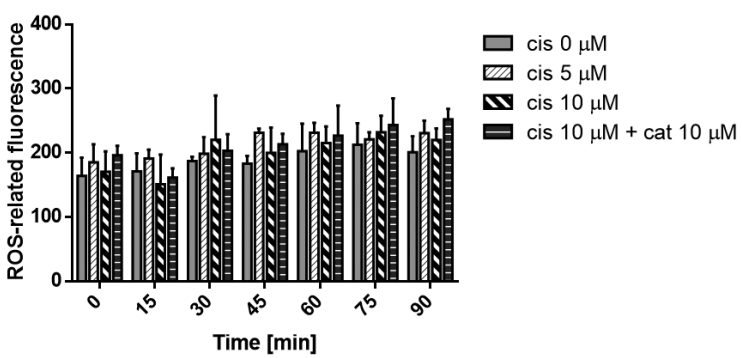

Figure 4. The results of DCF assay following the $4 \mathrm{~h}$ incubation with cisplatin preceded by catechin preincubation (10 $\mu \mathrm{M}$ for 24 hours or $50 \mu \mathrm{M}$ for 2 hours) in PDA cell line EPP85-181P (sensitive to daunorubicin; A, B) and EPP85-181RNOV (multidrug-resistant; C, D) measured every 15 min for 90 minutes.

Table 1. The comparison of the immunoreactivity of the mitochondrial superoxide dismutase (SOD2) and glutathione S-transferase (GST) in PDA cell lines EPP85-181P (sensitive to daunorubicin) and EPP85-181RNOV (multidrug-resistant) not preceded by catechin preincubation versus preceded by incubation with $10 \mu \mathrm{M}$ catechin for 24 hours or with $50 \mu \mathrm{M}$ catechin for 2 hours.

\begin{tabular}{lllllll}
\hline & W/o incubation & & $24 \mathrm{~h}, 10 \mu \mathrm{M}$ Cat & $2 \mathrm{~h}, 50 \mu \mathrm{M}$ Cat \\
\hline & \% of stained cells & reaction strength & $\%$ of stained cells & reaction strength & $\%$ of stained cells & reaction strength \\
\hline & EPP85-181P & & & & \\
\hline SOD2 & 100 & + & 100 & ++ & 100 & $++/+++$ \\
\hdashline GST & 100 & ++ & 100 & ++ & 100 & ++ \\
\hline & EPP85-181RNOV & & & & 100 \\
\hline SOD2 & 85 & + & 97 & $+/++$ & 100 & $++/+++$ \\
\hdashline GST & 40 & $+/-$ & 100 & $++/+++$ & $++/+++$ \\
\hline
\end{tabular}

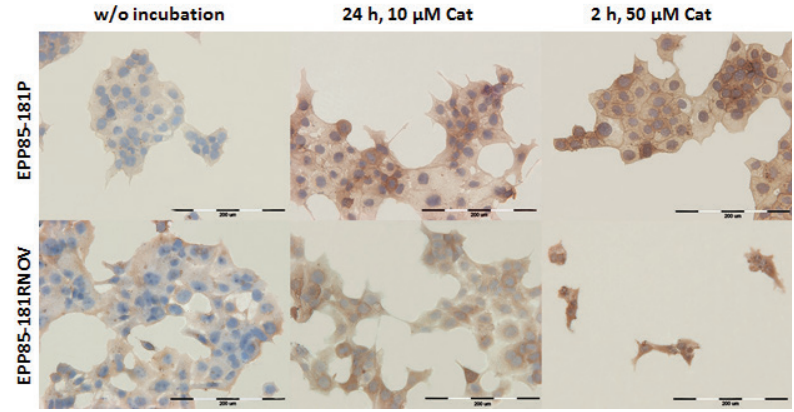

Figure 5. The representative photographs of the immunoreactivity of the mitochondrial superoxide dismutase (SOD2) in PDA cell lines EPP85-181P (sensitive to daunorubicin) and EPP85181RNOV (multidrug-resistant) not preceded by catechin preincubation versus preceded by incubation with $10 \mu \mathrm{M}$ catechin for 24 hours or with $50 \mu \mathrm{M}$ catechin for 2 hours.

The scale bars in the bottom right corner of each microphotography refer to $200 \mu \mathrm{m}$.

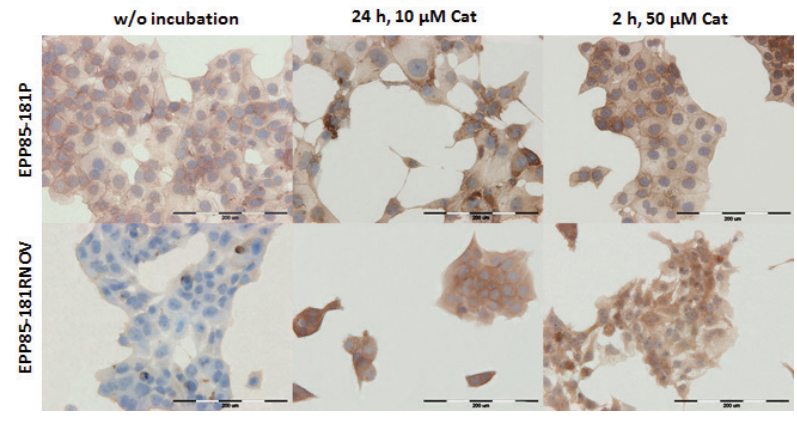

Figure 6. The representative photographs of the immunoreactivity of the glutathione S-transferase (GST) in PDA cell lines EPP85-181P (sensitive to daunorubicin) and EPP85-181RNOV (multidrug-resistant) not preceded by catechin preincubation versus preceded by incubation with $10 \mu \mathrm{M}$ catechin for 24 hours or with $50 \mu \mathrm{M}$ catechin for 2 hours.

The scale bars in the bottom right corner of each microphotography refer to $200 \mu \mathrm{m}$. 
EPP85-181P

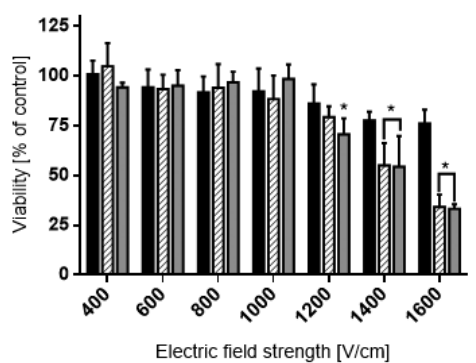

EPP85-181RNOV

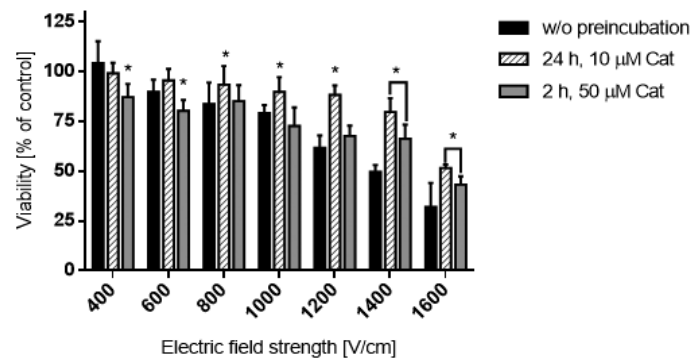

Figure 7. The viability of PDA cells EPP85-181P (sensitive to daunorubicin) and EPP85-181RNOV (multidrug-resistant) measured with MTT assay following exposition to the electric field strength at a range of $0-1600 \mathrm{~V} / \mathrm{cm}$ after $48 \mathrm{hours}$ of incubation when not preceded by catechin preincubation versus preceded by incubation with $10 \mu \mathrm{M}$ catechin for 24 hours or with $50 \mu \mathrm{M}$ catechin for 2 hours.

${ }^{*}$ statistically significant differences between groups treated with catechin and non-treated control $(p \leq 0.05)$.

$181 \mathrm{P}$ (Table 1) and the effect was stronger for the shorter incubation with $50 \mu \mathrm{M}$ catechin (Fig. 5). At the same time, the immunoreactivity of the glutathione S-transferase remained stable, regardless of the time of incubation and concentration of catechin (Table 1). More apparent changes occurred in the atypical drug-resistant cells EPP85-181RNOV, in which the increase of the GST exceeded the increase of the SOD2 immunoreactivity, especially after incubation with $50 \mu \mathrm{M}$ catechin, which was reflected by the percentage of stained cells and strength of the reaction (Table 1). Additionally, short incubation with the higher concentration of catechin resulted in the disturbed morphology of the multidrug-resistant cells, which was manifested inter alia via shrinkage of the cytoplasm and the appearance of the atypical protrusive structures (Fig. 5 and 6).

The electrosensitivity of PDA cells with and without catechin preincubation

The multidrug-resistant cell line EPP85-181RNOV is characterized by a stronger sensitivity to the higher pulsed electric field than the parental cell line EPP85$181 \mathrm{P}$ (Fig. 7). In case of the application of $1600 \mathrm{~V} /$ $\mathrm{cm}$, the viability measured by the MTT assay in sensitive cells decreased by approximately 34\%. The same EP parameter in the multidrug-resistant cells resulted

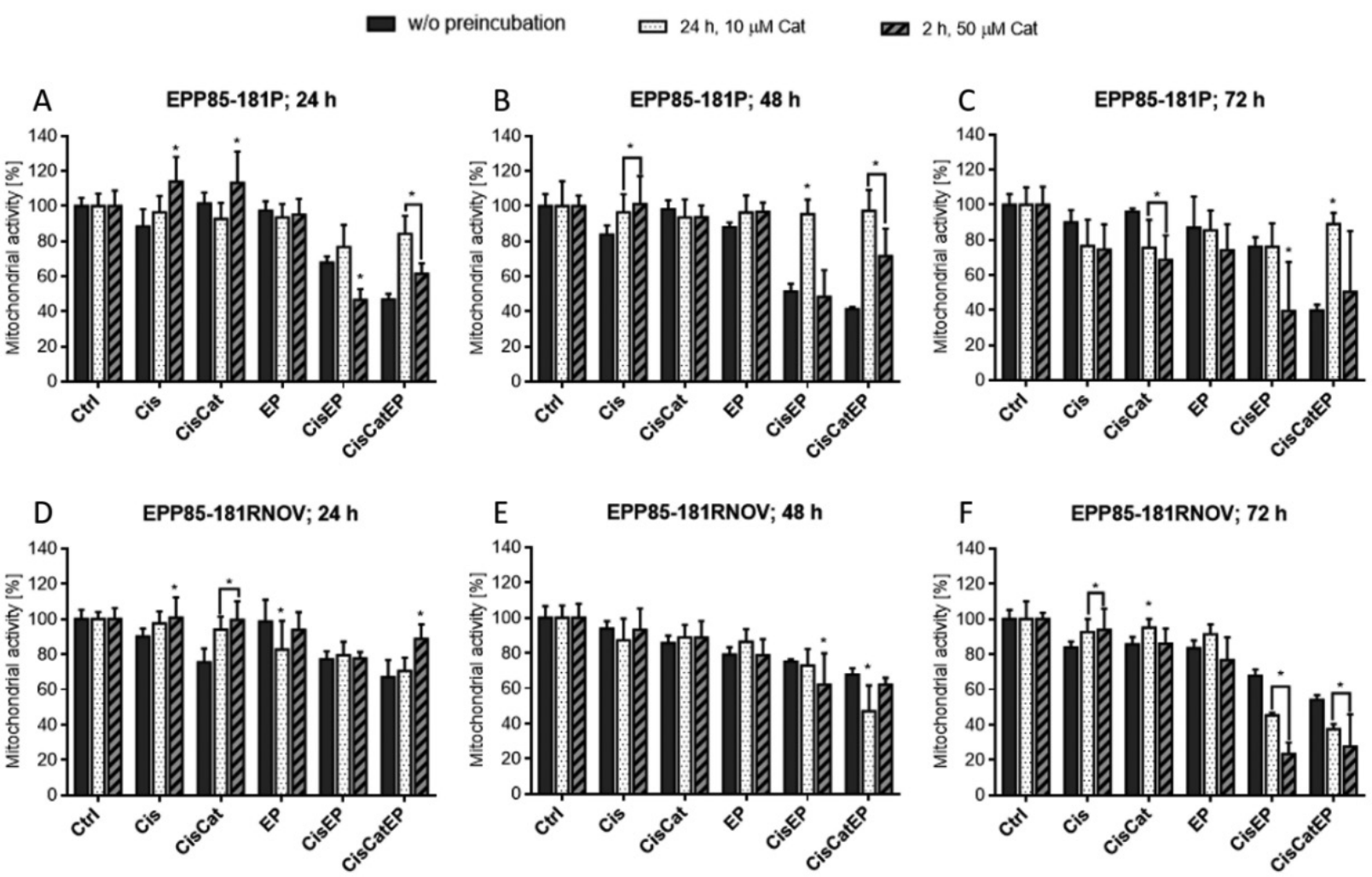

Figure 8. The viability of EPP85-181P and EPP85-181RNOV cells, measured with MTT aasay, following the electrochemotherapy in vitro with cisplatin not supported versus supported by the catechin preincubation.

$\mathrm{Ctrl}$ - non-treated control, Cis - $10 \mu \mathrm{M}$ cisplatin, CisCat - mix of the $10 \mu \mathrm{M}$ cisplatin and $10 \mu \mathrm{M}$ catechin, EP - electroporation $1000 \mathrm{~V} /$ $\mathrm{cm}$, CisEP - Cis supported by EP, CisCatEP - CisCat supported by EP. * ${ }^{*}$ statistically significant differences between groups treated with catechin and non-treated control $(p \leq 0.05)$. 

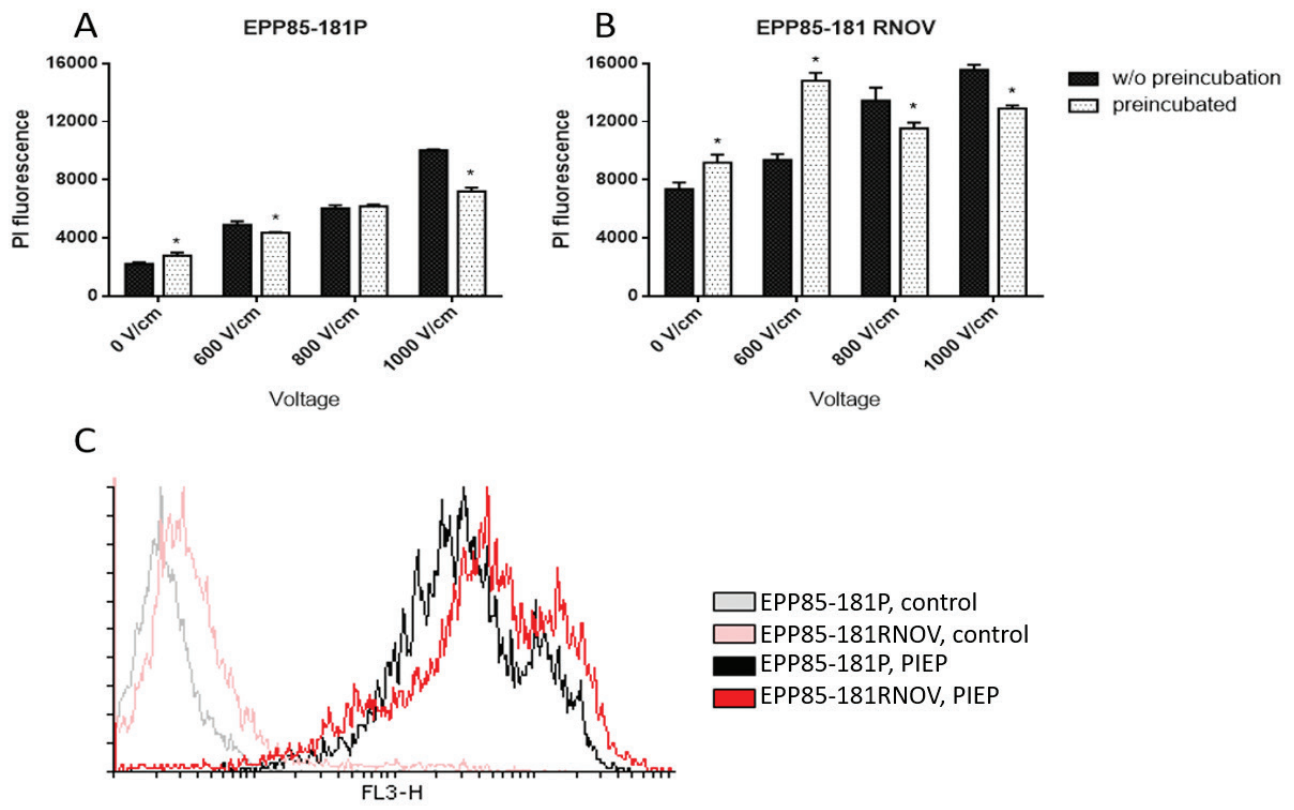

Figure 9. The fluorescence of the propidium iodide (PI) after EP with $10 \mu \mathrm{M}$ PI concentration in PDA cell lines EPP85-181P (sensitive to daunorubicin) and EPP85-181RNOV (multidrug-resistant) not preceded by catechin preincubation versus preceded by incubation with $50 \mu \mathrm{M}$ catechin for 2 hours.

PIEP - electroporation $(1000 \mathrm{~V} / \mathrm{cm})$ with $10 \mu \mathrm{M}$ propidium iodide. *statistically significant differences between groups treated with catechin and non-treated control $(p \leq 0.05)$.

in a significant drop by nearly $68 \%$ after 48 -hour incubation $(p \leq 0.05)$. Interestingly, the preincubation with catechin influenced the electrosensitivity of PDA cells in a manner opposite to the one obtained in a cisplatin chemosensitivity testing - while preincubation seemed to protect resistant cells against negative effects of higher voltages, the same incubation time and concentrations of catechin evoked the decreased viability of the parental cells EPP85-181P.

\section{Electrochemotherapy in vitro}

Electroporation with cisplatin preceded by catechin preincubation

The results of the electroporation with cisplatin clearly show that the influence of catechin concentration and time of incubation are not unequivocal for the multidrug-resistant and the drug-sensitive cell line. In the parental cells EPP85-181P the viability after CisEP meas-
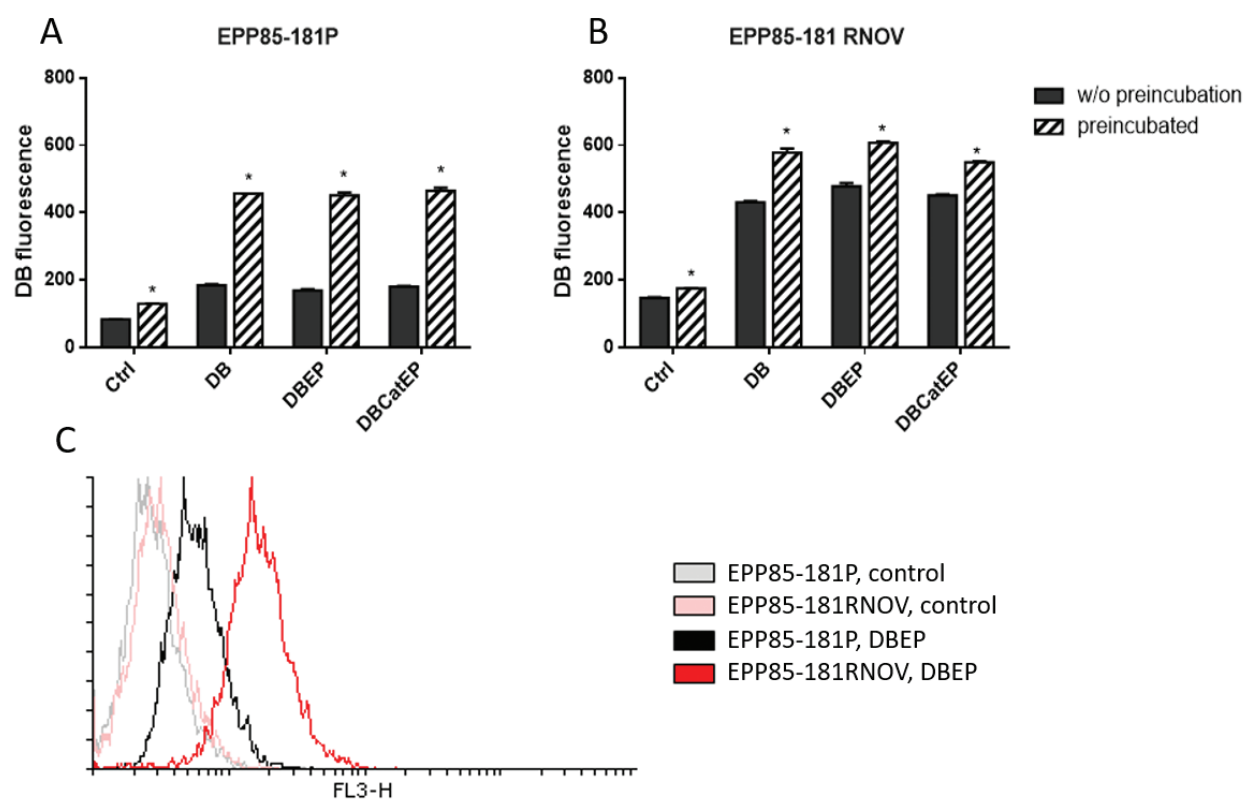

EPP85-181P, control

EPP85-181RNOV, control

EPP85-181P, DBEP

EPP85-181RNOV, DBEP

Figure 10. The fluorescence of the daunorubicin in PDA cell lines EPP85-181P (sensitive to daunorubicin) and EPP85-181RNOV (multidrug-resistant) after electroporation $(1000 \mathrm{~V} / \mathrm{cm})$ with daunorubicin $(1 \mu \mathrm{M})$ not preceded by catechin preincubation versus preceded by preincubation with $50 \mu \mathrm{M}$ catechin for 2 hours.

Ctrl - non-treated control, DB - incubation with daunorubicin, DBEP - electroporation with daunorubicin, DBCatEP - electroporation with daunorubicin and $10 \mu \mathrm{M}$ catechin. * statistically significant differences between groups treated with catechin and non-treated control $(p \leq 0.05)$. 
ured via MTT assay was significantly higher when the cells were subjected to 24-hour catechin preincubation (Fig. 8A, B). However, this effect was less detectable after 72 hours of incubation (Fig. 8C). The same parameters significantly reduced the viability of the multidrugresistant cells after 72 hours of incubation (Fig. 8F). The effect of shorter incubation with $50 \mu \mathrm{M}$ of cisplatin is more comparable between cell lines after 72 - hour incubation. In both cell lines cisplatin combined with EP induced higher cytotoxicity when cells were subjected to the preincubation with catechin (Fig. 8C, F). However, after 24 hours this effect was visible only in case of the parental cells and not for the EPP85-181RNOV cell line (Fig. 8A, D). Interesting results were obtained when 10 $\mu \mathrm{M}$ catechin had been added to the cuvette with cisplatin just before the electroporation. Our results showed that the short exposition to the low concentration of catechin activated the protective mechanisms in PDA cells not subjected to the electroporation. However, when cisplatin and catechin (CisCatEP) were simultaneously delivered by electroporation to the cells not subjected to preincubation, there was revealed stronger anticancer effect in the sensitive cells $(p \leq 0.05)$. On the other hand, the differences between CisEP and CisCatEP in cells subjected to preincubation were minor. When cells were preincubated, the additional dose of catechin resulted in either slight protection in sensitive cells after the short preincubation with catechin (Fig. 8A, B) or by the slight enhancement in the cisplatin cytotoxicity in the resistant cells subjected to 24-hour preincubation (Fig. 8D, E, F).

The uptake of the propidium iodide and daunorubicin

The experiment with the propidium iodide showed that in both cell lines not exposed to electroporation the uptake of the PI was bigger in cells preincubated with catechin prior to the procedure (Fig. 9). However, when the electroporation was applied, this effect occurred only in multidrug-resistant cells for the low voltage $(600 \mathrm{~V} /$ $\mathrm{cm})$, whereas for the higher parameters the outcome was the opposite in both - the drug-sensitive and the drugresistant cell line.

The uptake of the daunorubicin was significantly increased via catechin preincubation (Fig. 10). On the other hand, when catechin was applied shortly during electroporation process-the daunorubicin transportation was not improved (Fig. 10A, B - DBCatEP).

It is noteworthy, that the multidrug-resistant cells "absorbed" more propidium iodide and daunorubicin than the cells from the parental cell line EPP85-181P (Fig. 9C; Fig. 10C).

\section{DISCUSSION}

Numerous studies have demonstrated the possible role of green tea bioflavonoids in the anticancer therapy. The best studied catechin is epigallocatechin gallate (EGCG) in which green tea is the richest. The vast majority of studies is focused on the antioxidative activity of green tea polyphenols, which can include direct mechanisms, such as scavenging of reactive oxygen species (ROS) or indirect action, like activation of antioxidant enzymes, inhibition of oxidases, mitigation of oxidative stress caused by nitric oxide or the increase in the antioxidant properties of low molecular antioxidants (Procházková et al., 2011). The activity of the flavonoid is determined by the configuration and the total number of hydroxyl groups (Heim et al., 2002). The difference between catechin and EGCG is the lack of the trihydroxyl structure in the D ring (gallate). The B ring hydroxyl configuration is the most significant determinant of ROS scavenging (Burda \& Oleszek, 2001), whereas the substitution of rings $\mathrm{A}$ and $\mathrm{C}$ has little impact on superoxide anion radical scavenging rate constants (Taubert et al., 2003; Amić et al., 2007; Procházková et al., 2011). Hence, we believe that antioxidant properties of catechin may be similar to EGCG.

Surprisingly, despite the huge popularity of green tea, data on the bioavailability of individual green tea products are still limited. Imai and coworkers revealed that a cup of green tea provides $80-106 \mathrm{mg}$ of polyphenols (Imai et al., 1997). Most of these polyphenols are methylated, glucuronidated and sulfated metabolites in blood plasma and urine. It has been found, that several presystemic processes contribute to the low oral bioavailability of green tea catechins (Lee et al., 2002; Wu et al., 2012). These include chemical degradation, intestinal metabolism, microbial metabolism, hepatic metabolism, poor membrane permeability and efflux transporter-mediated intestinal excretion (Sarma et al., 2008). Almost all the orally-administered green tea catechins are retained in the stomach until $60 \mathrm{~min}$, but a portion is absorbed into the bloodstream from the intestines, temporally accumulated in the liver, and then returned through the bile to the colon (Shimizu et al., 2014). This indicates high role of the first-pass effect in catechin bioavailability (Yong Feng, 2006). Hence, catechin should be administrated parenterally and that explains higher plasma concentration of green tea compounds when drug was administrated intravenously (Lee et al., 2002; Yong Feng, 2006; Janle et al., 2008). For catechin hydrate, the maximum reported plasma concentration was $12.17 \mu \mathrm{g} / \mathrm{mL}$ at an intravenous dose of $20 \mathrm{mg} / \mathrm{kg}$ in rats (Wu et al., 2012). In our study, we used catechin concentrations ranging from 1 to $29 \mu \mathrm{g} / \mathrm{mL}$. Concentrations used for preincubations were $2.9 \mu \mathrm{g} / \mathrm{mL}$ and $14.5 \mu \mathrm{g} / \mathrm{mL}$ (for 24- and 2-hour, respectively), which are physiologically achievable with intravenous or intratumoral injection. However, our study did not include the examination of intracellular catechin concentration. Furthermore, the direct interaction between catechin molecules and cellular membrane should be examined in subsequent studies to fully understand the role of catechin on the electropermeabilization process.

In our investigation, we examined the influence of catechin preincubation on the neutralization of the reactive oxygen species via DCF assay. In general, the cells subjected to the short preincubation with $50 \mu \mathrm{M}$ were characterized by a lower level of ROS than those incubated for 24 hours with $10 \mu \mathrm{M}$ catechin and the differences were more prominent for the multidrug-resistant cell line. In the study by Jun-ichi Ueda and coworkers (1996) catechol compounds including catechin greatly suppressed the generation of $\bullet \mathrm{OH}$ from the reaction of $\mathrm{Cu}(\mathrm{en})_{2}$ with $\mathrm{H}_{2} \mathrm{O}_{2}$ by forming ternary $\mathrm{Cu}(\mathrm{en})(\mathrm{L})$ complexes (Ueda $e t$ al., 1996). However, EGCG can also autoxidize and produce hydrogen peroxide in culture media with and without cells (Kim et al., 2014). The autoxidative action of the catechin via the production of the hydrogen peroxide may be limited because of the lack of the pyrogallol moiety; however, this is not the only mechanism leading to the ROS generation. EGCG was also found to trigger the Fenton reaction via the reduction of $\mathrm{Fe}(\mathrm{III})$ to $\mathrm{Fe}(\mathrm{II})$ and hereby creating more potent reactive oxygen species (ROS) such as hydroxyl radicals in the human $\mathrm{T}$ lymphocyte Jurkat cells, in which $50 \mu \mathrm{M}$ EGCG generated about $1 \mu \mathrm{M}$ of hydrogen peroxide (Nakagawa et al., 2004). The study conducted on the non-small-cell lung 
cancer-derived cell line H1299 has shown that EGCG led to the ROS formation in a dose-dependent manner, and the effect was attenuated by the addition of SOD/ catalase (Li et al., 2010). In the study 25 and $50 \mu \mathrm{M}$ concentrations of EGCG were applied for 12 and 24 hours. In our research, cells were incubated with $50 \mu \mathrm{M}$ catechin only for 2 hours, which could explain the differences in the ROS-scavenging activity. Importantly, we have found that catechin may also have an indirect impact on cells. In our study, the immunoreactivity of the superoxide dismutase increased in both - the parental and the multidrug-resistant cell line. The intensity of the immunocytochemical reaction of the glutathione S-transferase changed only in the EPP85-181RNOV cells. The most visible changes occurred in cells preincubated with $50 \mu \mathrm{M}$ catechin. This, in turn, may suggest that the catechin may be also involved in the oxidative stress generation and have a toxic effect on the pancreatic cancer cells. In the study conducted by Yamamoto and coworkers (2004) antioxidant $\mathrm{N}$-acetyl-l-cysteine rescued the tumor cells from $\mathrm{H}_{2} \mathrm{O}_{2}$-induced damage only, but not from EGCG-induced mitochondrial damage, which suggests the existence of mechanisms for the mitochondrial damage not related to hydrogen peroxide (Yamamoto et al., 2004). On the other hand, in the in vivo study, the EGCG prevented the free fatty acids-induced peripheral insulin resistance through its antioxidative action leading to the decreased plasma markers of oxidative stress: malondialdehyde (MDA) and 8-isoprostaglandin, and the increased antioxidant enzymes: superoxide dismutase and glutathione peroxidase ( $\mathrm{Li}$ et al., 2011). The discrepancies between EGCG activity in different in vivo and in vitro studies may be explained, among others, by the different amount of antioxidants, including glutathione, thioredoxin, catalase and SOD in various tissues and serum components (Kim et al., 2014).

The study conducted on lung tumor xenograft mice model showed that oral administration of EGCG is associated with the induction of oxidative stress and DNA damage in tumor cells. Most importantly, this effect applied only to cancer cells and was not observed in normal cells (Li et al., 2010). This difference was subsequently assigned to sirtuin 3 (SIRT3), an important mitochondrial redox modulator (Tao et al., 2015). In our investigation, the most apparent differences after catechin incubation were obtained in a multidrug-resistant cell line EPP85-181RNOV. There are several mechanisms which can explain the increased effects of catechins on the particularly resistant cells. The first one is the impact of the green tea flavonoids on P-gp expression. The investigation carried out on the P-gp overexpressing cellosaurus cell line showed that catechins can decrease the accumulation of P-gp substrates (rhodamine-123 and daunorubicin) and this inhibitory effect was not correlated with their total hydrophobicity, but depended significantly on their chemical structure (Kitagawa et al., 2004). Another study showed that the green tea polyphenols can inhibit the photolabeling of P-gp by $75 \%$ and increase the accumulation of rhodamine-123 3-fold in the multidrugresistant cellosaurus and epithelial colorectal adenocarcinoma cells, indicating the interaction with P-gp (Jodoin et al., 2002). Interestingly, this modulation was reversible. Tang and coworkers found that EGCG suppressed the MDR-1 expression in resistant cells (Tang et al., 2017). The study by Zhu and coworkers revealed that tea polyphenol could improve the uptake of $99 \mathrm{mTc}$-tetrofosmin (a substrate for P-gp) in MCF-7/Adr cells (Zhu et al., 2001). On the contrary, a different study on MDCKII cells transfected with hPgp, hMRP1, and hMRP2 showed that EGCG and its methyl metabolites are substrates for MRP1 and MRP2, but not for P-gp (Hong et al., 2003). In our examination, we used parental cell line of pancreatic cancer and atypical derivative with MDR1/P-gp-independent multidrug-resistance. Therefore, P-gp mitigation is clearly not the reason of the increased potency of catechin in resistant cells, and there have to be different mechanisms involved. Indeed, EGCG has been shown to inhibit the cell proliferation and induce apoptosis in various cancer cells inter alia by blocking the activation of the epidermal growth factor receptor (EGFR) family of RTKs (Shimizu et al., 2011). Furthermore, EGCG inhibited fatty acid synthase in intact cells and selectively induced apoptosis in prostate cancer cells, but the epicatechin which does not inhibit the fatty acid synthase had no effect on cells' growth and viability (Brusselmans et al., 2003). EGCG has been demonstrated to inhibit telomerase, topoisomerase II and DNA methyltransferase 1 , thus ultimately affecting chromatin maintenance and remodeling (Patra et al., 2008). Overexpression of the topoisomerase II is one of the leading mechanism of EPP85-181RNOV drug-resistance (Lage \& Dietel, 2002), so this might explain the stronger response of the cell line to the catechin incubation. However, this issue should be examined in a separate investigation.

In our investigation, there was a synergistic effect of the low-dosage cisplatin application with and without electroporation, but the effect was visible only in the multidrug-resistant cells and not in the parental ones. The synergistic anti-cancer effect of green tea catechins in combination with other anti-tumor medicines such as cisplatin, docetaxel, 5-fluorouracil and paclitaxel on various tumors has been revealed in many reports (Ramadass et al., 2015; Zhang et al., 2015; Meng et al., 2017; Yuan et al., 2017). The combination of the cisplatin and the green tea polyphenols has been studied in vitro and in vivo (Chan et al., 2006; Mazumder et al., 2012). It has been shown, that polyphenols and cisplatin can synergistically inhibit the growth of various cancer cells, such as MCF-7 breast cancer cells and non-small cell lung cancer A549 cells (Cao et al., 2016). The co-treatment of cisplatin and EGCG induced apoptosis of the resistant ovary and the lung cancer cells by targeting expression of the CTR1 (Wang et al., 2015; Jiang et al., 2016). Co-treatment of tea polyphenols and cisplatin can also decrease proliferation and induce apoptosis in breast cancer cells (Chen \& Zhen, 2013). These reports suggest that catechins could be useful, multifunctional drugs in the treatment of chemo-resistant cancer cells. Our study revealed that catechin preincubation have increased the intercellular accumulation of doxorubicin. Unfortunately, the results from FACS analysis cannot be directly related to viability assay results because of different chemotherapeutics (doxorubicin and cisplatin). Interestingly, in both experiments Cat augmented drug uptake or effect, in particular in combination with electroporation. The main mechanism of doxorubicin resistance is connected to P-gp overexpression, which is clearly not the aim in our research. Hence, the obtained results suggest that Cat can sensitize cell membrane in different manners. Once by the modulation of drug resistance proteins (involving the P-gp expression and other MDR proteins) and second by sensitizing cell membrane, enhancing the intracellular drug accumulation.

Catechin preincubation exhibited a protective role towards EPP85-181P cells and enhanced drug toxicity in multidrug-resistant cells, which has been shown in chemosensitivity tests (Fig. 2). On the other hand, when cells were subjected to the action of pulsed electric field, 
the effects were exactly opposite. Remarkably, multidrugresistant cell lines appear to be more sensitive to higher voltage than sensitive cancer cells and normal cell lines which has been observed also during electrochemotherapy (Gehl, 2005; Kulbacka et al., 2014), irreversible electroporation (Neal et al., 2011) and on 3D culture models (Frandsen et al., 2015). Frandsen et al. (2016) explains that phenomenon by the more effective membrane repair in normal, primary cells in comparison to the resistant cancer cells (Frandsen et al., 2016). In case of our study, the protective effect apparent in multidrug-resistant cells especially for the low concentration of catechin does not have to be unfavorable. The ultimate aim is to increase the effectiveness of the electrochemotherapy, and not irreversible electroporation. The mitigation of the electrosensitivity by natural compounds enables the application of higher voltage while still promoting electropermeabilization and not necrosis within the cell population. It is worth noticing, that in case of the internal cancers, such as pancreatic adenocarcinoma, the favored type of cell death is apoptosis.

In conclusion, our research revealed for the first time, that the pre-treatment with catechin increased the efficacy of cisplatin with electroporation which was reflected by the decreased viability of the human pancreatic cancer cells. Although transcriptional regulation is one of the explanations of the green tea polyphenol's effectiveness, that may not be the leading mechanisms responsible, as the best results were obtained only 2 hours after treatment. Short incubation with a higher concentration of catechin in general was more effective in direct scavenging the ROS but was simultaneously involved in the oxidative stress generation which was also found in different studies. Hence, it seems that the strict determination catechins as antioxidants loses relevance, especially in the face of its growing applicability in the anticancer studies. Our research demonstrates that co-treatment of standard cytostatic and natural compounds such as catechin from green tea can significantly improve the effectiveness of electrochemotherapy. We believe that catechin effects on cellular response and membrane permeabilization are worth a further examination.

\section{Conflicts of Interest}

The authors declare that there are no conflicts of interest.

\section{Acknowledgments}

The study was presented and awarded on the 5th European Joint Theoretical/Experimental Meeting on Membranes. We would like to thank Prof. M. Kotulska from the Wrocław University of Science and Technology (Wrocław, Poland) for the possibility of performing electroporation experiments on ECM 830 Square Wave Electroporation System (BTX, Syngen Biotech, Poland). We also wish to acknowledge prof. H. Lage from the Institute of Pathology, Campus Mitte, Charité University Hospital (Berlin, Germany) for granting us access to the EPP85-181P and EPP85-181RNOV cell lines and kind permission to utilize them in this investigation. We would also like to thank Ms. E. Przydatek for help with the correction of the English language in the manuscript.

\section{Acknowledgments of fiancial Support}

This work was supported by funds from the project of Wroclaw Medical University (Poland) STM.A040.17.039 (PI: Jolanta Saczko).
This work has been published with the financial support of Prof. Z. Wasylewski Foundation for Faculty of Biochemistry, Biophysics and Biotechnology, Jagiellonian University.

\section{REFERENCES}

Amić D, Davidović-Amić D, Beslo D, Rastija V, Lucić B, Trinajstić N (2007) SAR and QSAR of the antioxidant activity of flavonoids. Curr Med Chem 14: 827-845

Appari M, Babu KR, Kaczorowski A, Gross W, Herr I (2014) Sulforaphane, quercetin and catechins complement each other in elimination of advanced pancreatic cancer by miR-let-7 induction and Kras inhibition. Int J Oncol 45: 1391-1400. doi: 10.3892/ijo.2014.2539

Balentine DA, Wiseman SA, Bouwens LCM (1997a) The chemistry of tea flavonoids. Crit Rev Food Sci Nutr 37: 693-704

Basu A, Haldar S (2009) Combinatorial effect of epigallocatechin3-gallate and TRAIL on pancreatic cancer cell death. Int J Oncol 34: 281-286

Brusselmans K, De Schrijver E, Heyns W, Verhoeven G, Swinnen J V (2003) Epigallocatechin-3-gallate is a potent natural inhibitor of fatty acid synthase in intact cells and selectively induces apoptosis in prostate cancer cells. Int J Cancer 106: 856-862. doi: 10.1002/ ijc.11317

Burda S, Oleszek W (2001) Antioxidant and antiradical activities of flavonoids. J Agric Food Chem 49: 2774-2779

Cao J, Han J, Xiao H, Qiao J, Han M (2016) Effect of tea polyphenol compounds on anticancer drugs in terms of anti-tumor activity, toxicology, and pharmacokinetics. Nutrients 8: doi: 10.3390/nu8120762

Chan MM, Soprano KJ, Weinstein K, Fong D (2006) Epigallocatechin3 -gallate delivers hydrogen peroxide to induce death of ovarian cancer cells and enhances their cisplatin susceptibility. J Cell Physiol 207: 389-396. doi: 10.1002/jcp.20569

Chen C, Wu C, Yang TH, Chang Y, Sheu ML, Liu S (2016) Green tea catechin prevents hypoxia/reperfusion-evoked oxidative stressregulated autophagy-activated apoptosis and cell death in microglial cells. J Agric Food Chem 64: 4078-4085. doi: 10.1021/acs. jafc.6b01513

Chen S-Z, Zhen Y-S (2013) Molecular targets of tea polyphenols and its roles of anticancer drugs in experimental therapy. Yao Xue Xue Bao 48: 1-7

Ferlay J, Soerjomataram I, Dikshit R, Eser S, Mathers C, Rebelo M, Parkin DM, Forman D, Bray F (2015) Cancer incidence and mortality worldwide: Sources, methods and major patterns in GLOBOCAN 2012. Int J Cancer 136: E359-E386. doi: 10.1002/ijc.29210

Forester SC, Lambert JD (2011) The role of antioxidant versus prooxidant effects of green tea polyphenols in cancer prevention. Mol Nutr Food Res 55: 844-854. doi: 10.1002/mnfr.201000641

Frandsen SK, Gibot L, Madi M, Gehl J, Rols M-P (2015) Calcium Electroporation: Evidence for Differential Effects in Normal and Malignant Cell Lines, Evaluated in a 3D Spheroid Model. PLoS One 10: e0144028. doi: 10.1371/journal.pone.0144028

Frandsen SK, McNeil AK, Novak I, McNeil PL, Gehl J (2016) Difference in Membrane Repair Capacity Between Cancer Cell Lines and a Normal Cell Line. J Membr Biol 249: 569-576. doi: 10.1007/ s00232-016-9910-5

Gehl J (2005) Investigational treatment of cancer using electrochemotherapy, electrochemoimmunotherapy and electro-gene transfer. $U g$ eskr Laeger 167: 3156-3159

Goess R, Friess H (2018) A look at the progress of treating pancreatic cancer over the past 20 years. Expert Rev Anticancer Ther 18: 1-10. doi: 10.1080/14737140.2018.1428093

Granata V, Fusco R, Piccirillo M, Palaia R, Petrillo A, Lastoria S, Izzo F (2015) Electrochemotherapy in locally advanced pancreatic cancer: Preliminary results. Int J Surg 18: 230-236. doi: 10.1016/j. ijsu.2015.04.055

Granata V, Fusco R, Setola SV, Piccirillo M, Leongito M, Palaia R, Granata F, Lastoria S, Izzo F, Petrillo A (2017) Early radiological assessment of locally advanced pancreatic cancer treated with electrochemotherapy. World J Gastroenterol 23: 4767. doi: 10.3748/wjg. v23.i26.4767

Hagen RM, Chedea VS, Mintoff CP, Bowler E, Morse HR, Ladomery MR (2013) Epigallocatechin-3-gallate promotes apoptosis and expression of the caspase 9a splice variant in PC3 prostate cancer cells. Int J Oncol 43: 194-200. doi: 10.3892/ijo.2013.1920

Heim KE, Tagliaferro AR, Bobilya DJ (2002) Flavonoid antioxidants: chemistry, metabolism and structure-activity relationships. J Nutr Biochem 13: 572-584

Hong J, Lambert JD, Lee SH, Sinko PJ, Yang CS (2003) Involvement of multidrug resistance-associated proteins in regulating cellular levels of (-)-epigallocatechin-3-gallate and its methyl metabolites. Biochem Biophys Res Commun 310: 222-227. doi: 10.1016/j. bbrc. 2003.09 .007 
Hosseinimehr SJ, Rostamnejad M, Ghaffari-rad V (2013) Epicatechin enhances anti-proliferative effect of bleomycin in ovarian cancer cell. Res Mol Med 1: 24-27

Hussain T, Gupta S, Adhami VM, Mukhtar H (2005) Green tea constituent epigallocatechin-3-gallate selectively inhibits COX-2 without affecting COX-1 expression in human prostate carcinoma cells. Int J Cancer 113: 660-669. doi: 10.1002/ijc.20629

Ilic M, Ilic I (2016) Epidemiology of pancreatic cancer. World J Gastroenterol 22: 9694-9705. doi: 10.3748/wig.v22.i44.9694

Imai K, Suga K, Nakachi K (1997) Cancer-preventive effects of drinking green tea among a Japanese population. Prev Med (Baltim) 26: 769-775

Janle EM, Morré DM, Morré DJ, Zhou Q, Zhu Y (2008). Pharmacokinetics of green tea catechins in extract and sustained-release preparations. Journal of dietary supplements, J Diet Suppl 5: 248-263. doi: 10.1080/19390210802414279.Pharmacokinetics.f

Jiang P, Wu X, Wang X, Huang W, Feng Q (2016) NEAT1 upregulates EGCG-induced CTR1 to enhance cisplatin sensitivity in lung cancer cells. Oncotarget 7: 43337-43351. doi: 10.18632/oncotarget.9712

Jodoin J, Demeule M, Beliveau R (2002) Inhibition of the multidrug resistance P-glycoprotein activity by green tea polyphenols. Biochim Biophys Acta-Molecular Cell Res 1542: 149-159. doi: 10.1016/s01674889(01)00175-6

Katiyar SK, Mukhtar H (1997) Tea antioxidants in cancer chemoprevention. I Cell Biochem 67: 59-67. doi: 10.1002/(SICI)10974644(1997)27+<59::AID-JCB11>3.0.CO;2-G

Kim H-S, Quon MJ, Kim J (2014) New insights into the mechanisms of polyphenols beyond antioxidant properties; lessons from the green tea polyphenol, epigallocatechin 3-gallate. Redox Biol 2: 187195. doi: 10.1016/j.redox.2013.12.022

Kitagawa S, Nabekura T, Kamiyama S (2004) Inhibition of P-glycoprotein function by tea catechins in KB-C2 cells. I Pharm Pharmacol 56: 1001-1005. doi: 10.1211/0022357044003

Kommalapati A, Tella SH, Goyal G, Ma WW, Mahipal A (2018) Contemporary management of localized resectable pancreatic cancer. Cancers 10: 24. doi: 10.3390/cancers10010024

Kulbacka J, Daczewska M, Dubińska-Magiera M, Choromańska A, Rembiałkowska N, Surowiak P, Kulbacki M, Kotulska M, Saczko J (2014) Doxorubicin delivery enhanced by electroporation to gastrointestinal adenocarcinoma cells with P-gp overexpression. Bioelectrochemistry 100: 96-104. doi: 10.1016/j.bioelechem.2014.03.013

Lage H, Dietel M (2002) Multiple mechanisms confer different drugresistant phenotypes in pancreatic carcinoma cells. J Cancer Res Clin Oncol 128: 349-357. doi: 10.1007/s00432-002-0349-y

Lee MJ, Maliakal P, Chen L, Meng X, Bondoc FY, Prabhu S, Lambert G, Mohr S, Yang CS (2002) Pharmacokinetics of tea catechins after ingestion of green tea and (-)-epigallocatechin-3-gallate by humans: Formation of different metabolites and individual variability. Cancer Epidemiol Biomarkers Prev 11: 1025-1032

Li GX, Chen YK, Hou Z, Xiao H, Jin HY, Lu G, Lee MJ, Liu B, Guan F, Yang ZH, Yu A, Yang CS (2010) Pro-oxidative activities and dose-response relationship of (-)-epigallocatechin-3-gallate in the inhibition of lung cancer cell growth: a comparative study in vivo and in vitro. Carcinogenesis 31: 902-910. doi: 10.1093/carcin/bgq039

Li Y, Zhao S, Zhang W, Zhao P, He B, Wu N, Han P (2011) Epigallocatechin-3-O-gallate (EGCG) attenuates FFAs-induced peripheral insulin resistance through AMPK pathway and insulin signaling pathway in vivo. Diabetes Res Clin Pract 93: 205-214. doi: 10.1016/J. DIABRES.2011.03.036

Long J, Luo G Pei, Xiao Z Wen, Liu Z Qiang, Guo M, Liu L, Liu C, Xu J, Gao Y tang, Zheng Y, Wu C, Ni Q Xing, Li M, Yu X (2014) Cancer statistics: Current diagnosis and treatment of pancreatic cancer in Shanghai, China. Cancer Lett 346: 273-277. doi: 10.1016/j. canlet.2014.01.004

Martin RC, McFarland K, Ellis S, Velanovich V (2013) Irreversible electroporation in locally advanced pancreatic cancer: Potential improved overall survival. Ann Surg Oncol 20: 443-449

Mazumder MEH, Beale P, Chan C, Yu JQ, Huq F (2012) Epigallocatechin gallate acts synergistically in combination with cisplatin and designed trans-palladiums in ovarian cancer cells. Anticancer Res 32: 4851-4860

Meng J, Tong Q, Liu X, Yu Z, Zhang J, Gao B (2017) Epigallocatechin-3-gallate inhibits growth and induces apoptosis in esophageal cancer cells through the demethylation and reactivation of the p16 gene. Oncol Lett 14: 1152-1156. doi: 10.3892/ol.2017.6248

Nakagawa H, Hasumi K, Woo J-T, Nagai K, Wachi M (2004) Generation of hydrogen peroxide primarily contributes to the induction of $\mathrm{Fe}(\mathrm{II})$-dependent apoptosis in Jurkat cells by (-)-epigallocatechin gallate. Carcinogenesis 25: 1567-1574. doi: 10.1093/carcin/bgh168

Neal RE, Rossmeisl JH, Garcia PA, Lanz OI, Henao-Guerrero N, Davalos R V. (2011) Successful treatment of a large soft tissue sarcoma with irreversible electroporation. J Clin Oncol 29: e372-e377. doi: 10.1200/JCO.2010.33.0902

Patra SK, Rizzi F, Silva A, Rugina DO, Bettuzzi S (2008) Molecular targets of (-)-epigallocatechin-3-gallate (EGCG): specificity and in- teraction with membrane lipid rafts. I Physiol Pharmacol 59 Suppl 9: $217-235$

Procházková D, Boušová I, Wilhelmová N (2011) Antioxidant and prooxidant properties of flavonoids. Fitoterapia 82: 513-523. doi: 10.1016/J.FITO'TE.2011.01.018

Qanungo S, Das M, Haldar S, Basu A (2005) Epigallocatechin-3-gallate induces mitochondrial membrane depolarization and caspasedependent apoptosis in pancreatic cancer cells. Carcinogenesis 26: 958-967. doi: 10.1093/carcin/bgi040

Ramadass SK, Anantharaman NV, Subramanian S, Sivasubramanian S, Madhan B (2015) Paclitaxel/Epigallocatechin gallate coloaded liposome: A synergistic delivery to control the invasiveness of MDAMB-231 breast cancer cells. Colloids Surfaces B Biointerfaces 125: 65-72. doi: 10.1016/j.colsurfb.2014.11.005

Ruarus A, Vroomen L, Puijk R, Scheffer H, Meijerink M (2018) Locally advanced pancreatic cancer: a review of local ablative therapies. Cancers 10: 16. doi: 10.3390/cancers10010016

Roy SK, Srivastava RK, Shankar S (2010) Inhibition of PI3K/AKT and MAPK/ERK pathways causes activation of FOXO transcription factor, leading to cell cycle arrest and apoptosis in pancreatic cancer. I Mol Signal 5: 10, doi: 10.1186/1750-2187-5-10

Sang SM, Lambert JD, Ho CT, Yang CS (2011) The chemistry and biotransformation of tea constituents. Pharmacol Res 64: 87-99. doi: 10.1016/j.phrs.2011.02.007

Sarma DN, Barrett ML, Chavez ML, Gardiner P, Ko R, Mahady GB, Marles RJ, Pellicore LS, Giancaspro GI, Low Dog T (2008) Safety of green tea extracts: A systematic review by the US Pharmacopeia. Drug Saf 31: 469-484. doi: 10.2165/00002018-200831060-00003

Schuijer M, Berns EMJJ (2003) TP53 and Ovarian Cancer. Hum Mutat 21: 285-291. doi: 10.1002/humu.10181

Shen G, Xu C, Hu R, Jain MR, Nair S, Lin W, Yang CS, Chan JY, Kong A-NT (2005) Comparison of (-)-epigallocatechin-3-gallate elicited liver and small intestine gene expression profiles between C57BL/6J mice and C57BL/6J/Nrf2 (-/-) mice. Pharm Res 22: 1805-1820. doi: 10.1007/s11095-005-7546-8

Shimizu M, Adachi S, Masuda M, Kozawa O, Moriwaki H (2011) Cancer chemoprevention with green tea catechins by targeting receptor tyrosine kinases. Mol Nutr Food Res 55: 832-843. doi: 10.1002/ mnfr.201000622

Shimizu K, Asakawa T, Harada N, Fukumoto D, Tsukada H, Asai T, Yamada S, Kan T, Oku N (2014) Use of positron emission tomography for real-time imaging of biodistribution of green tea catechin. PLoS One 9: doi: 10.1371/journal.pone.0085520

Song Y, Sun H, Zhang A, Yan G, Han Y, Wang X (2014) Plantderived natural products as leads to anti-cancer drugs. I Med Plant Herb Ther Res 2: 6-15

Tang H, Zeng L, Wang J, Zhang X, Ruan Q (2017) Reversal of 5-fluorouracil resistance by EGCG is mediate by inactivation of TFAP2A/VEGF signaling pathway and down- regulation of MDR1 and P-gp expression in gastric cancer. Oncotarget 8: 82842-82853

Tao L, Park J, Lambert JD (2015) Differential prooxidative effects of the green tea polyphenol, (-)-epigallocatechin-3-gallate, in normal and oral cancer cells are related to differences in sirtuin 3 signaling. Mol Nutr Food Res 59: 203-211. doi: 10.1002/mnfr.201400485

Taubert D, Breitenbach T, Lazar A, Censarek P, Harlfinger S, Berkels R, Klaus W, Roesen R (2003) Reaction rate constants of superoxide scavenging by plant antioxidants. Free Radic Biol Med 35: 1599-1607. doi: 10.1016/J.FREERADBIOMED.2003.09.005

Ueda J, Saito N, Shimazu Y, Ozawa T (1996) A Comparison of Scavenging Abilities of Antioxidants against Hydroxyl Radicals. Arch Biochem Biophys 333: 377-384. doi: 10.1006/ABBI.1996.0404

Vroomen L, Petre EN, Cornelis FH, Solomon SB, Srimathveeravalli G (2017) Irreversible electroporation and thermal ablation of tumors in the liver, lung, kidney and bone: What are the differences? Diagn Interv Imaging 98: 609-617. doi: 10.1016/j.diii.2017.07.007

Wang X, Jiang P, Wang P, Yang CS, Wang X, Feng Q (2015) EGCG enhances cisplatin sensitivity by regulating expression of the copper and cisplatin influx transporter CTR1 in ovary Cancer. PLoS One 10: e0125402. doi: 10.1371/journal.pone.0125402

Wong MCS, Jiang JY, Liang M, Fang Y, Yeung MS, Sung JJY (2017) Global temporal patterns of pancreatic cancer and association with socioeconomic development. Sci Rep 7: 3165. doi: 10.1038/s41598017-02997-2

Wu L, Zhang QL, Zhang XY, Lv C, Li J, Yuan Y, Yin FX (2012) Pharmacokinetics and blood-brain barrier penetration of $(+)$-Catechin and $(-)$-Epicatechin in rats by microdialysis sampling coupled to high-performance liquid chromatography with chemiluminescence detection. I Agric Food Chem 60: 9377-9383. doi: 10.1021/ jf $301787 \mathrm{f}$

Yamamoto T, Lewis J, Wataha J, Dickinson D, Singh B, Bollag WB, Ueta E, Osaki T, Athar M, Schuster G, Hsu S (2004) Roles of catalase and hydrogen peroxide in green tea polyphenol-induced chemopreventive effects. J Pharmacol Exp Ther 308: 317-323. doi: 10.1124/ jpet.103.058891

Yong Feng W (2006) Metabolism of green tea catechins: an overview. Curr Drug Metab 7: 755-809. doi: 10.2174/138920006778520552 
Yuan C-H, Horng C-T, Lee C-F, Chiang N-N, Tsai F-J, Lu C-C, Chiang J-H, Hsu Y-M, Yang J-S, Chen F-A (2017) Epigallocatechin gallate sensitizes cisplatin-resistant oral cancer CAR cell apoptosis and autophagy through stimulating AKT/STAT3 pathway and suppressing multidrug resistance 1 signaling. Environ Toxicol 32: 845855. doi: 10.1002 /tox. 22284

Zhang N, Zhang H, Xia L, Zheng Y, Yu Y, Zhu Y, Chen G, Di W (2009) NSC606985 induces apoptosis, exerts synergistic effects with cisplatin, and inhibits hypoxia-stabilized HIF-1 a protein in human ovarian cancer cells. Cancer Lett 278: 139-144. doi: 10.1016/j.canlet.2008.12.025
Zhang Q, Zeng L, Chen Y, Lian G, Qian C, Chen S, Li J, Huang K (2016) Pancreatic cancer epidemiology, detection, and management. Gastroenterol Res Practice 2016. doi: 10.1155/2016/8962321

Zhang Y, Wang X, Han L, Zhou Y, Sun S (2015) Green tea polyphenol EGCG reverse cisplatin resistance of A549/DDP cell line through candidate genes demethylation. Biomed Pharmacother 69: 285290. doi: 10.1016/j.biopha.2014.12.016

Zhu A, Wang X, Guo Z (2001) Study of tea polyphenol as a reversal agent for carcinoma cell lines' multidrug resistance (study of TP as a MDR reversal agent). Nucl Med Biol 28: 735-740 